\title{
ПРОБЛЕМЫ ИССЛЕДОВАНИЯ ПСИХОЛОГИЧЕСКОЙ ДОСТОВЕРНОСТИ И ИДЕАЛЬНОЙ СЛЕДОВОЙ ИНФОРМАЦИИ В СУДЕБНОЙ ПСИХОЛОГИИ
}

\section{PROBLEMS OF RESEARCH OF PSYCHOLOGICAL RELIABILITY AND IDEAL TRACE INFORMATION IN FORENSIC PSYCHOLOGY}

\section{Yu. Kozlachkova}

Summary: The article presents a review of forensic and legal sources concerning a study of the terms "reliability and perfect tracks", their legal entity and different scientific interpretations, demonstrates their debatable nature. Special attention is paid to the exposure of possible constraints of using of these terms in forensic psychological examination and causes of their occurrence. As a result of the study the author formulated theoretic and practical recommendations of using the terms "reliability" and "perfect tracks" in theory and practice of forensic psychological examination.

Keywords: forensic psychological examination, perfect tracking information, psychological reliability, testimony credibility, information reliability assessment, perfect tracks research.
$\Pi$ роблема обнаружения, изучения, интерпретации и фиксации информации, которой обладают участники или очевидцы какого-либо события, а также оценка степени ее полноты и объективности (достоверности) является одной из наиболее актуальных для всех субъектов процессуальной деятельности как в рамках уголовного, так и гражданского и арбитражного судопроизводства. Носителем такой информации является человек, а следовательно, степень ее полноты и достоверности, а также возможность соответствующей вербальной передачи заинтересованным лицам находится в прямой зависимости в первую очередь от таких факторов, как сохранность высших психических функций (восприятия, памяти, речи, и т.д.) и их отличительных особенностей, характерных для конкретного индивида. Все перечисленные факторы входят в предмет исследования психологии, в связи с чем их изучение требует применения специальных познаний в этой научной сфере и является прерогативой специалиста либо эксперта. В то же время вопросы исследования психологической достоверности сообщаемой в ходе процессуальной деятельности информации являются предметом многочисленных научных исследований и дискуссий, связанных, в том числе, с необходимостью соблюдения установленных законодательством пределов компетенции экс-

\author{
Козлачкова Юлия Игоревна \\ судебный эксперт-психолог, Аспирант, Финансовый \\ университет при Правительстве РФ \\ YIKozlachkova2020@edu.fa.ru
}

Аннотация: В статье приведен обзор научных и правовых источников по вопросам исследования юридической сущности и научно-отраслевых толкований терминов достоверность и идеальные следы, продемонстрирован дискуссионный характер данных вопросов. Особое внимание уделено выявлению возможных препятствий к использованию указанных терминов в судебной экспертологии и причин их возникновения. По результатам исследования автором сформулированы теоретические и практические рекомендации по использованию понятий достоверность и идеальная следовая информация в теории и практике судебно-психологической экспертизы.

Ключевые слова: судебно-психологическая экспертиза, идеальная следовая информация, психологическая достоверность, правдивость показаний, полиграф, оценка достоверности информации, исследование идеальных следов.

перта. Особую важность эта проблема приобретает в рамках уголовного судопроизводства, налагающего высокие требования к соблюдению пределов компетенции каждого участника уголовного процесса, а также к терминологической точности. Дискуссионный характер данного вопроса имеет непосредственное влияние на практическую экспертную деятельность: отсутствие единого теоретического подхода к данной проблематике обусловливает появление и использование при формулировании экспертных задач иных терминов, таких как идеальная следовая информация, инсценировка коммуникации и пр.

Вопросы исследования достоверности сообщаемой информации в целом и, в частности - психологической достоверности показаний до недавнего времени широко освещались в научной, в том числе периодической литературе и изложены в работах многих российских и зарубежных ученых (С.К. Хаидова [15], А.М. Багмета [8], В.Ф. Енгалычева [6], А.В. Моисеева [9], Ф.С. Сафуанова $[12]$, П. Экмана [16] и др.) и до недавнего времени являлись дискуссионными.

Действующим российским уголовно-процессуальным законодательством установлено, что оценка досто- 
верности показаний, как и других видов доказательств, относится к исключительной компетенции дознавателя, следователя, прокурора, суда [3], что создает проблемы в использовании этого термина при назначении и производстве экспертизы в рамках уголовного судопроизводства, которое обоснованно можно считать основным направляющим вектором в развитии судебной экспертологии. О понимании данной проблемы свидетельствует и мнение профессионального сообщества. Так, в 2016 г. опубликовано информационное письмо за подписью ведущих исследователей в сфере судебной психологии, содержащее критику попытки отдельных ученых разделить понятия юридической и психологической достоверности, а также следующий вывод: «учитывая положения уголовно-процессуального законодательства Российской Федерации и состояние научно-исследовательских разработок в области свидетельских показаний, в настоящее время установление достоверности показаний путем назначения и проведения судебной экспертизы (психологической, психолого-психиатрической, какой-либо иной) на строго научной основе невозможно» [13]. Очевидно, что подобные выводы будут по умолчанию распространяться на показания других участников уголовного процесса, обладающих информацией об интересующем событии - подозреваемых, обвиняемых и потерпевших.

Аналогичной позиции придерживается и высший судебный орган в отношении использования при назначении или проведении экспертизы формулировки «правдивость показаний». Так, например, в одном из решений Верховный Суд Российской Федерации (далее - ВС РФ) указывает следующее: «основанием для назначения экспертиз явилась необходимость установления «правдивости», «добровольности» и «самостоятельности» показаний, то есть перед экспертом был поставлен ряд вопросов, которые фактически сводились к разрешению единого вопроса о достоверности показаний подозреваемых при производстве с ними следственных действий. Данные вопросы не могли быть поставлены на разрешение эксперта, поскольку согласно ст. 8 Уголовно-процессуального кодекса Российской Федерации (далее - УПК РФ), во взаимосвязи со ст.ст. 17, 87, 88 УПК РФ, вопросы о достоверности или недостоверности доказательств отнесены к исключительной компетенции следователя или суда. С учетом изложенного, приведенные в приговоре в качестве доказательств заключения эксперта по результатам судебно-психологических экспертиз видеозаписей, а также показания указанного эксперта в судебном заседании не могут признаваться допустимыми доказательствами.» [2]

Ни научное сообщество, ни законодатель не отрицает и не оспаривает тот факт, что именно особенности высших психических функций обусловливают содержание переданной уполномоченным должностным лицам про- цессуально значимой информации, а исследование этих особенностей относится к компетенции психологической науки. В то же время при пересечении понятийного аппарата задействованных в решении одной проблемы юридических и естественных наук главенствующее значение должно безусловно принадлежать юридической терминологии. Так, при наличии устоявшейся правоприменительной практики, официального и доктринального толкования термина «достоверность» в уголовном процессе, попытка обособить и пояснить понятие «психологическая достоверность» в рамках процессуальных документов приводит научное сообщество в тупик.

С учетом изложенного автор счел необходимым обратиться к изучению теоретических аспектов и границ формирования понятийного аппарата судебной экспертологии в целом.

Большинство авторов научных исследований связывают развитие судебной экспертологии как самостоятельной области научного знания со становлением и расширением сети судебно-экспертных учреждений, и лишь немногочисленные авторы научных исследований отмечают тот факт, что теория судебной экспертизы берет свои начала от криминалистической экспертизы, которая, в свою очередь эволюционно отделилась от криминалистики [5, С.89]. Согласно Е.Р. Россинской, «новая наука синтетической природы - общая теория судебной экспертизы, она возникла в недрах криминалистики и переживает этап формирования. Для теории и практики экспертизы криминалистика играет роль обосновывающего знания, как и другие науки, например, физическая химия, молекулярная биология» [11].

Отделение теории судебной экспертизы в самостоятельную научную ветвь, по мнению автора настоящего исследования, было обусловлено в первую очередь следующими факторами:

- узкоспецифичным по отношению к криминалистике предметом исследования;

- необходимостью соблюдения жестких процессуальных рамок (пределов компетенции), в том числе при выборе тактических и методических приемов при производстве экспертиз;

- потребностью в адаптации используемой терминологии процессуальным требованиям, их корректировке с учетом законодательно установленных пределов компетенции эксперта и, как следствие - формированием собственного узкоспециального понятийного аппарата.

Так, с точки зрения автора, именно потребность в адаптации используемой терминологии требованиям уголовно-процессуального законодательства в настоящее время исключает возможность использования при назначении и производстве одного из видов судебной 
экспертизы - психологической экспертизы таких оценочных терминов, как достоверность, правдивость, лживость и т.п. Очевидно, что попытка решения экспертом вопроса о достоверности показаний создает видимость того, что в задачи исследования входит оценка доказательства, что не соответствует действительности. При этом изучение в комплексе психологических явлений, сопряженных с предоставлением участником уголовного процесса недостоверной информации, бесспорно, входит в предмет исследования психологии.

В то же время одной из основных задач судебной экспертологии, как и криминалистики, является изучение, интерпретация и фиксация следовой информации и механизмов ее образования с использованием специальных познаний. Исследователями в области криминалистики за время развития этой науки выработаны фундаментальные подходы к определению понятия следовой информации и ее классификации. В этой связи представляется не только возможным, но и целесообразным использование в судебной экспертологии в целом и, в частности, в судебной психологии научного понятийного аппарата криминалистики в той части, в которой он не противоречит установленным процессуальным требованиям. Терминологический аппарат криминалистики в силу специальной профессиональной подготовки хорошо известен и понятен должностным лицам органов, осуществляющих оперативно-розыскную деятельность, дознание и следствие, а также суду, а именно эти органы государственной власти являются основными «заказчиками» и «потребителями» экспертных исследований и определяют приоритетные направления их развития.

Апеллируя к понятийному аппарату криминалистики, в целях настоящего исследования необходимо в первую очередь обратить особое внимание на учение о следах.

По мнению О.Я. Баева, следы - единственный материал, с которым работает любой субъект уголовно-процессуального исследования преступлений [5, С. 196]. Любое, в том числе криминальное, событие - это взаимодействие между собой как минимум двух объектов. Такие взаимодействия проявляются в виде следов- отображений следообразующего объекта на объекте воспринимающем. Это принципиальнейшая посылка для всех наук, изучающих прошлое, реконструирующих события, уже происшедшие, будь то история, археология, криминалистика, и она обоснована материалистической гносеологией и теорией отражения. При этом Баев О.Я. склоняется к той точке зрения, что следом являются лишь те материальные или идеальные изменения, которые на современном этапе развития криминалистики мы осознаем, как след. Осознание же таких изменений как след осуществляется перманентно-поступательно по мере того, как криминалистика создает методики извлечения (обнаружения, фиксации), исследования и использования в целях познания и реконструкции преступных событий.

По мнению автора настоящего исследования, такая трактовка понятия следа является крайне актуальной для развития судебной психологии. Это связано с тем, что ряд ученых и правоприменителей (ВС РФ), отрицающих возможность изучения достоверности информации в рамках экспертизы (в том числе с использованием полиграфа), обосновывают свою позицию не только законодательными ограничениями, но и отсутствием научно обоснованных методик подобного исследования [1].

Всю следовую информацию, или криминалистически значимые отображения преступной деятельности, по общему основанию принято классифицировать на:

- материальные следы - «отпечатки» события на любых материальных объектах: предметах, документах, теле и организме потерпевшего, обстановке события и т.д.

- идеальные следы - отпечатки события в сознании, памяти людей, совершивших преступление, и к нему прикосновенных (например, укрыватели преступления и т.п.), потерпевших от преступления, очевидцев, других свидетелей и т.д.; в связи с таким характером этих следов их еще именуют интеллектуальными, или «памятными» следами [4].

Р.С. Белкин справедливо отмечает, что механизм возникновения идеальных изменений и сами эти изменения, как мысленные образы в сознании людей - участников или посторонних наблюдателей события, являются объектом исследования криминалистики лишь отчасти, поскольку криминалистика черпает основные данные об этих процессах из психологии (общей и судебной), физиологии и других наук о человеке [4, Т. 2 С. 57].

Данное утверждение не только не исключает возможность исследования механизмов возникновения идеальных следов, но и подчеркивает необходимость применения в этих целях специальных знаний в области психологии человека. Автору представляется, что в данной ситуации область исследования механизма возникновения идеальных следов, безусловно, относится к предмету судебной экспертологии, а именно - судебной психологии, однако это вовсе не исключает нахождение этого предмета в сфере исследования криминалистики, для нужд которой применяются как частно-научные методы психологии, так и других наук (химии, медицины, физики, психологии).

В современных условиях идеальные следы признаются самостоятельным видом следов практически всеми учеными-криминалистами [10]. Проблеме исследования идеальной следовой информации в криминалистике 
посвящена кандидатская диссертация Л.А. Суворовой, которая предложила создание криминалистической энграммологии как отдельного учения в рамках следоведения [14]. Вместе с тем, вопрос о возможности изучения идеальных следов в рамках судебно-психологической экспертизы представлен только единичными исследованиями авторов. Так, Арпентьева М.Р. и Макаренко И.А. полагают возможным ставить на разрешение экспертапсихолога следующую задачу: «Имеется ли у потерпевшего ... идеальная следовая информация относительного того, что... (фактические обстоятельства)?» [6]. Принципиально соглашаясь с возможностью решения подобных задач в рамках судебной психологии, автор считает необходимым указать на некоторые несовершенства предлагаемой формулировки, которые могут поставить под сомнение научную обоснованность экспертных выводов.

Во-первых, в соответствии с общей теорией криминалистики, следователь как субъект криминалистической деятельности осуществляет сбор релевантной информации, имеющейся у участника уголовного процесса (потерпевшего, подозреваемого, обвиняемого, свидетеля) и ее изложение на материальном носителе в форме протокола допроса, который является ничем иным, как результатом фиксации идеальных следов преступления. В отличие от тех случаев, когда для обнаружения и фиксации материальных следов необходимы специальные познания (например, для обнаружения отпечатков пальцев), для которых вопрос «Имеются ли на объекте следы рук?» является традиционным, в случае с идеальными следами УПК РФ возлагает на лицо, производящее процессуальные действия, обязанность их фиксации, в том числе путем допроса (по аналогичным принципам осуществляется оперативно-розыскная деятельность). Протокол допроса, как правило, входит в предмет изучения судебного эксперта-психолога. С учетом этого обстоятельства, исходя из указанной выше формулировки вопроса, эксперту-психологу предлагается самостоятельно и обособленно от лица, производящего расследование, получить у участника уголовного процесса идеальную следовую информацию и сопоставить ее с информацией, изложенной в протоколе допроса. Таким образом, предложенная формулировка завуалированным образом возлагает на эксперта отдельные функции следователя, и в этой связи представляется несовершенной. Необходимо иметь в виду, что к моменту назначения экспертизы процессуальное лицо уже должно принять меры к получению и фиксации идеальной следовой информации, а эксперт-психолог с использованием специальных знаний может исследовать механизмы ее формирования.

Во-вторых, самостоятельное и обособленное получение экспертом идеальной следовой информации предполагает использование научно обоснованных методик, позволяющих работать с ней только с применением специальных познаний. Как представляется автору, до настоящего времени в научных источниках не описаны какие-либо методики, которые бы позволяли эксперту-психологу «с нуля» реконструировать описываемые обследуемым события либо констатировать отсутствие таких событий. Вероятно, предложения отдельных исследователей выделить в отдельный раздел криминалистики энграммологию, которая позволяла бы работать с памятью человека, когда-либо будут реализованы, однако автор полагает, что к настоящему времени для этого отсутствует какая-либо научная основа.

В связи с изложенным постановка перед экспертом задачи в форме «Имеются ли у... идеальные следы относительно событий.» является ничем иным, как заимствованием формулировок у иных направлений экспертологии, изучающих материальные следы.

Принимая во внимание изложенное, автор предлагает следующий вариант постановки задачи судебному эксперту-психологу, который полностью согласуется с частным предметом психологического исследования: «Каковы психологические особенности механизма формирования идеальной следовой информации, полученной от... в ходе процессуальных действий, и могли ли они существенно повлиять на его показания?»

При решении этой задачи эксперт, используя специальные знания в области психологии, устанавливает конкретный механизм формирования идеальных следов, зафиксированных в протоколе допроса: естественный (информация получена в ходе познавательных процессов), либо искусственный (информация является результатом работы мышления и воображения), либо смешанный (естественный процесс с элементами искусственного, либо наоборот).

Предложенная автором постановка задачи при любом ее толковании исключает двусмысленность и выход эксперта за пределы своей компетенции, в то же время не ограничивает свободу действий эксперта. Постановка такого вопроса не презюмирует, что идеальные следы обязательно содержатся в протоколе допроса. Если эксперт в ходе исследования сможет научными методами извлечь новую уголовно-релевантную информацию, то он имеет право ее зафиксировать.

Резюмируя изложенные доводы, можно сформулировать следующие выводы, к которым пришел автор относительно вопроса о проблемах и перспективах исследования «психологической достоверности» сообщаемой информации. Содержание информации, которая в той или иной форме сообщается в ходе процессуальной (например, оперативно-розыскной или уголовно-процессуальной) деятельности участником либо очевидцем 
какого-либо события, обусловлено в первую очередь индивидуальными особенностями высших психических функций человека и психологическими механизмами формирования сообщаемых им сведений. Так, в основе намеренной дезинформации со стороны участника уголовного процесса и сообщения им максимально полной информации об интересующем событии лежат различные психологические механизмы. Сообщение неполных или недостоверных сведений о противоправном деянии может быть и следствием неосознанных действий, связанных с индивидуальными психологическими особенностями восприятия. Исследование этих факторов, влияющих на полноту и достоверность показаний, требует специальных познаний в области психологии и в этой связи может быть предметом психологической судебной экспертизы. При этом необходимо иметь в виду следующее:

- до настоящего времени в научных источниках не описаны какие-либо валидизированные методики, которые бы позволяли эксперту-психологу «с нуля» полноценно реконструировать описываемые обследуемым события либо констатировать отсутствие таких событий;

- уголовно-процессуальное право определяет пределы компетенции эксперта и устанавливает границы терминологического аппарата судебной экспертологии. В этой связи использование в юридических документах, оформляемых при назначении и производстве экспертизы, термина «достоверность», в том числе в такой составной конструкции, как «психологическая достоверность», не представляется возможным. Решение этой проблемы возможно с опорой на устоявшиеся специальные неюридические термины, к определению которых сформировался единый научный подход.

В криминалистике традиционно считается, что следы - единственный материал, с которым работает любой участник уголовного процесса. При этом существует единый подход к определению идеальных следов (идеальной следовой информации), не оспаривается и утверждение ученых-криминалистов о том, что изучение идеальных следов входит в предмет исследования психологии. В то же время УПК РФ предусматривает обязательную фиксацию этих идеальных следов в протоколах следственных действий, которые становятся объектами экспертного исследования. В этой связи предлагается при постановке и решении вопроса об изучении идеальных следов формулировать экспертную задачу следующим образом: «Каковы психологические особенности механизма формирования идеальной следовой информации, полученной от (данные участника) в ходе процессуальных действий, и могли ли они существенно повлиять на его показания?»

\section{ЛИТЕРАТУРА}

1. Апелляционное определение Судебной коллегии по уголовным делам Верховного Суда Российской Федерации от 10.10.2019 N 57-AПУ19-5 URL: https:// legalacts.ru/sud/apelliatsionnoe-opredelenie-sudebnoi-kollegii-po-ugolovnym-delam-verkhovnogo-suda-rossiiskoi-federatsii-ot-10102019-n-57-apu19-5/ (дата обращения 29.07.2020)

2. Верховный суд Российской Федерации, Апелляционное определение судебной коллегии по уголовным делам по делу № 73-АПУ17-8 0т 07 июня 2017 г. URL: http://www.vsrf.ru/stor_pdf.php?id=1551406 (дата обращения 26.07.2020)

3. Уголовно-процессуальный кодекс Российской Федерации от 18.12.2001 № 174-Ф3 (ред. от 24.04.2020, с изМ. от 09.07.2020) // URL: www.consultant.ru (дата обращения 26.07.2020)

4. Белкин Р.С. Курс криминалистики: Криминалистические средства, приемы и рекомендации. В 3-х томах. - М.: Юристъ, 2016.

5. Баев 0.Я. Криминалистика. Лекционный курс: учебное пособие. 4-е изд., перераб. И доп. - Москва: Юстиция, 2017, - 372 с.

6. Макаренко И.А., Арпентьева М.Р. Методологические аспекты судебной экспертизы с вопросами исследования идеальных следов преступления // Академия образования Великобритании: научный журнал -2019-3(29) -C.84-92

7. Методика выявления признаков достоверности / недостоверности информации, сообщаемой участниками уголовного судопроизводства (по видеозаписям следственных действий и оперативно-разыскных мероприятий) : науч.-практ. пособие / А.М. Багмет и др. - М. : ФГБУ ГНЦ ФМБЦ им. А.И. Бур-назяна ФМБА России, Академия СК России

8. Моисеев А.В., Сотников Н.А., Кучерук Т.Р., Пимкина П.Ю. К вопросу о выявлении признаков достоверности / недостоверности показаний в ходе допроса // Вестник Омского университета. Серия «Психология». 2019. № 1. С. 46-56

9. Малыхина Н.И. Идеальные следы в криминалистике // Правовое государство - 2014 - 3(37) -C. 93-95 URL: https://cyberleninka.ru/article/n/idealnye-sledyv-kriminalistike/viewer (дата обращени 26.07.2020)

10. Россинская Е.Р. Криминалистика. Вопросы и ответы: Учеб. Пособие для вузов. - М. ЮНИТИ-ДАНА, 2000. - 351 с. -С.25

11. Сафуанов Ф.С., Шишков С.Н. Экспертиза «правдивости» показаний (Возможности психологической экспертизы) // Законность, 1992. - № 2. - С. 13-14.

12. Смирнова С.А., Макушкин Е.В., Аснис А.Я., Васкэ Е.В., Дозорцева Е.Г., Сафуанов Ф.С., Шишков С.Н., Шипшин С.С., Ошевский Д.С., Бердников Д.В., Секераж Т.Н., Калинина А.Н. Информационное письмо «0 неправомерности определения достоверности показаний путем судебной экспертизы». Теория и практика судебной экспертизы. -2016 -3(43) -C.64-73 URL: https://doi.org/10.30764/64/1819-2785-2016-3-64-73 (дата обращения 26.07.2020) 
13. Суворова Л.А. Идеальные следы в криминалистике: автореф. дис. кандидата психологических наук 12.00 .09 [Место защиты - Воронежский государственный университет] Воронеж, $2005-28 c$.

14. Хаидов С.К. Судебно-психологическая оценка признаков достоверности показаний при исследовании видеоматериалов: моногр. / С.К. Хаидов и др. Тула: ГОУ ДПО ТО ИПК и ПП РО ТО, 2016. - 113 с.

15. Экман П. Психология лжи 4-е изд.: Пер. с англ. - СПб.: Питер, 2018 - 304 с.

(c) Козлачкова Юлия Игоревна (YIKozlachkova2020@edu.fa.ru).

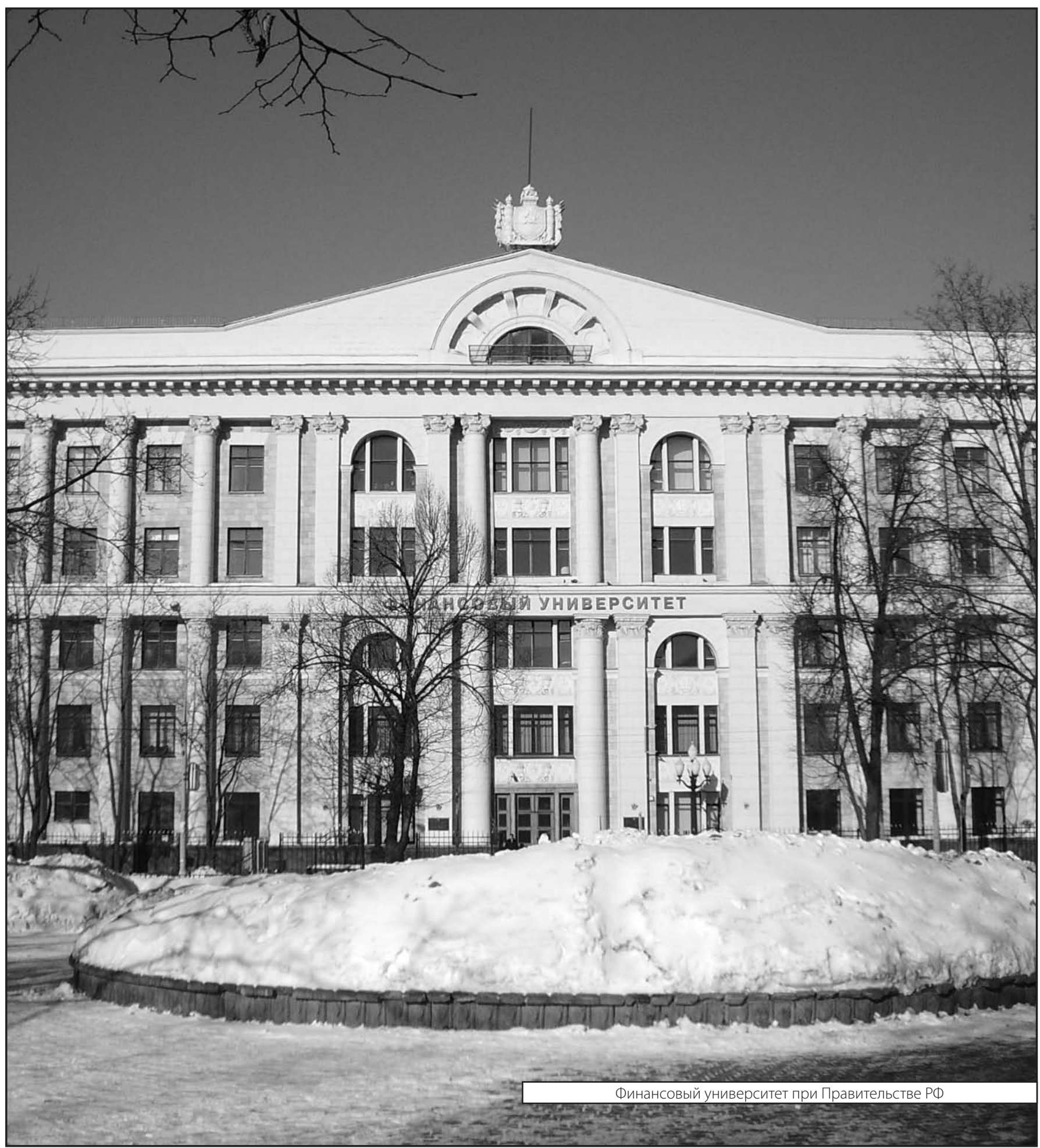

